\title{
Journey of ERP from Manufacturing to Education Industry
}

\author{
Prokreeti Mitra \\ School of Management, KIIT University, Bhubaneswar, India. \\ Sasmita Mishra \\ School of Management, KIIT University, Bhubaneswar, India.
}

\begin{abstract}
Enterprise Resource Planning (ERP) is a concept used to integrate the business process into one particular software in order to reduce work load. The technology had a very modest beginning and its popularity and efficiency is increasing day by day. This conceptual paper provides a historical sketch of the evolution of ERP and its journey from manufacturing set up to service and education sector. This study also intends to explore factors which leads to ERP usage in manufacturing, service and technical education institute. Finally, finds out certain gray areas of research in education industry.
\end{abstract}

Key Words: ERP, ERP usage, evolution of ERP, ERP modules, critical success factors.

\section{INTRODUCTION}

ERP is an acronym which stands for Enterprise Resource Planning (ERP), the term was coined in the year 1990 by The Gartner Group. Tracing back to the evolution, this software evolved from Material Requirement Planning (MRP) and Manufacturing Requirement Planning (MRPII) in 1970 and 1980. MRP and MRP II were designed to systematically link different aspects of process information with manufacturing business process. ERP has been described both as a concept and software. Initially ERP was concentrated only to manufacturing companies, but later due to its popularity and high range of acceptance, it has put its step into other sectors. ERP as a concept has many software. The popular ones are: SAP, JD Edwards, BANN, Microsoft Dynamics, Oracle and PeopleSoft. Before implementing ERP, organisations should always reengineer their business process according to their requirements. This process is called as Business Process Reengineering (BPR). BPR is basically a strategy to create a platform to implement ERP.

In the last decade, ERP has also entered the education sector. With the descent of information system (IS) and digitization education sector too has taken a giant leap which has gradually captured global attention. Future Scenario shows that there are many players ready to invest in education as well as training institutions with an aim of rapidly scaling up this sector. Higher education is at an emerging stage and will have potential growth in
Journal of Technology Management for Growing Economies Vol. 9 , No. 2 October, 2018 pp. $138-150$

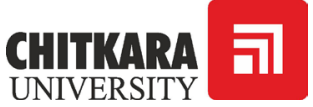

(C)2018 by Chitkara University. All Rights Reserved. 
the years to come. Vendors are coming up with educational ERP which is a comprehensive administration automation suite for all kinds of educational institutions such as schools, colleges, institutions or universities.

The requirements for automation in education sector has increased a lot. To provide massive user base and diverse requirements, there is requirement of education software that features and support for different operational models. Institutes today spend significant amount of time preparing for regulatory reports. Institutes can definitely look up to an ERP system for generating accurate reports. Therefore, for a good ERP system it is necessary to have a comprehensive out-of the-box regulatory compliance module that can bring ease to the creation of statutory reports. Thakur (2016) considered technical educational institutes (TEI) as finishing schools for young talents, which needs to be more transparent and effective. The ERP systems give the TEI a disciplined way to work and a better visibility to the institute.

According to Shatat \& Dana (2016) the operation of universities is very much different from that of the other organizations. With the increase in size of universities the implementation of ERP has become a must factor, as that will reduce the extra work load of data maintenance and administrative works, and in- return will provide quality service to staff and students (Nizamani \& Khoumbati, 2014). The implementation of ERP in universities is howsoever not an easy task, because ERP has very few core modules which is different from the functions of TEI, and it becomes problematic for universities to adopt these packaged systems as they need to alter their business process to fit into these systems. The small in house packages are not homogeneous structures but are rather heterogeneous structures which complicates integration with different structures (Bologa, Bologa, \& Sabau, 2009; Nizamani et al., 2014). Moreover, the educational institutes have the dearth of availability of experienced technical experts who fail to handle the in-house development of an enterprise-wide system (Esteves \& Pastor, 2005).

Despite of the difficulties, ERP has always proved to be useful to the students, faculties as well as administrative persons, where faculty and staff commonly interact for core institutional activities through ERPS, and students find it beneficial for more information and E-learning environments. The ERP systems are described as standard platforms for better decision making, information and institutional services (Abugabah \& Sanzogni, 2010). The need for ERP in institutions was also considered from the viewpoint to map the student feedback of two geographically separated students, address the issues of new e-centric business practices. The benefits derived from any ERP implementation should be assessed from 3 levels viz. researcher, university, broader business community (Goel, 2012).
Journey of

ERP from

Manufacturing 
Mitra, P.

Mishra, S.

140

\section{EVOLUTION OF INFORMATION SYSTEM (IS)}

Regardless of the fact of a booming or declining economy the main aim of any organisation is to see whether the investment made in any IS is successful or not. According to Keen (1980) IS can be described as "The effective design, delivery, use and impact of Information Technologies in organisations and society". There have been many theories relating to IS development and organizational change. The aim behind all the theories was to explain why innovation was so difficult and to implement proper strategies to manage the change. The IS community is explicitly concerned with improving the craft of design and the practice of management in the widest sense of both these terms. Simultaneously, it looks at information technologies with respect to organisation, people and society. The robustness of IT made it more voluminous, ubiquitous, and accessible. Relevance, accuracy and timeliness are still considered the success factors of IS. The evolution of IS has witnessed 5 eras(Petter, Delone, \& Mclean, 2012). They are as follows :-

Data Processing Era (1950-1960): This is the era when computers were used as sophisticated calculators for military and finance industry. This had helped in saving time but the information system was not of adequate quality which led to certain problems in the system.

Management reporting and decision support era (1960-1980): With the advancement of computer technology, people started using computer for monitoring and controlling productive business process and managing administrative work. The inability of using the system was not the lack of information data, but the inability of the manager/people to process the voluminous information.

Strategic and personal computing Era (1980-1990): During this era the managers actually started to feel the essence of information systems, through which they can achieve their organisational goals. In this era the love for personal computing increased and managers started to realize that with the help of personal computers productivity can make a shift forward. This will help companies to increase benefits. Thus, the job was shifted from back office to front office and computers were used more for the work process of employees. Another advancement in this era is the discovery of Technology Acceptance Model (TAM) which was based on Fishbein's (1975) Theory of Reasoned Action (TRA) and Theory of Planned Behaviour (TPB) which summarizes that for any individual to use the IS the user satisfaction has to work parallelly. This era focussed on the benefits individuals derived from IS. The focus was more on the socio-technological aspect of a system, where user satisfaction was the prime focus.

Journal of Technology Management for Growing Economies, Volume 9, Number 2, October 2018 
Enterprise system and Networking Era (1990-2000): In this era the data was shared with managers and other applicants rather than keeping it within the system or with a single individual. The emphasis was given more on enhancing collaboration among individuals and groups so that all come in one network. The ERP systems gained popularity in this era. Thus, many research and frameworks were made on the ERP systems. Looking into the efficiency of the ERP systems companies started to shell out enormously in implementing ERP. To get an inter organisational IS, they started to outsource their operational functions to increase productivity. The introduction of ERP, along with IS service quality, productivity and team performance was one of the key changes which happened in the Networking and ERP era. This era also witnessed the use of sophisticated information system within and across firms. But, a debate will arise with the change. Is the investment worthwhile? This is just like the "productivity paradox" happened in 1990 in which there was a concern that IT investments were not producing tangible benefits to firm. The issue was raised as whether systems have become commoditized and is no longer a competitive advantage .

Customer focused Era (2000 and beyond): This particular era witnessed the sophistication of IS. In this era the individuals have the potential to receive interest based on their personal interest. In the customer focused era, social media, networking, peer-to-peer computing were used not only for business productivity, but were used for hedonic use as entertainment. Governments are using IT for cutting costs, improve technology, improve service and make policy. This era focuses mainly on customers and services. The introduction of e-commerce was seen and this forced many of the managers to consider their websites as a powerful tool to generate interest. IS and technology now connect individuals globally, for business purpose as well as for personal reason.

In the past decade the technological and information sector has acquired a prominent place in the world economy, where ERP systems was the evolution output. ERP systems are used by organisations to do all their functions as planning, production management, sales management, finance management, human management. ERP stands for Enterprise Resource Planning. It is an acronym used by many IS companies to integrate their business process and help to maintain all data in one particular database. Thus, it is defined as an umbrella term which assimilates business software systems and controls a broad range of activities. It acts as glue that binds management functions across geographical sites with complex heterogeneous networks.
Journey of

ERP from

Manufacturing 
Mitra, P.

Mishra, S.

142

\section{EVOLUTION OF ERP}

Antero (2015) focuses on the origin of ERP and says that the concept of ERP can be traced back to the work of Blumenthal (1969), where he described the software as an integrated architectural framework, which he called as Total systems, which can also be used as organisational information systems. If we look more deeper, we see that Blumenthal's work was influenced by Jay Forrester's information-decision action model which describes that "information system is a network reaching into all parts of the firm.' Comparing the same with ERP systems, we can say that ERP is an integrated architectural framework which helps to connect various business of an organisations. The name change from manufacturing to enterprise signifies that the system is capable of linking the major business functions of any organisation, regardless of industry.

The evolution of ERP started long back and has occurred in different stages. Rashied in his work mentions that in the mid-20th century various departments in the organization started functioning independently, where they were termed as functional silos. Naturally they were deprived of the benefits of coordination. This marked the introduction of ERP systems. Later with the huge complexity of the organisation and highly competitive market organisations started searching for new technology to fulfil its functions and needs. hence witnessing the introduction of ERP systems. The evolution of ERP can be shown properly shown through a diagram as :-

MRP

MRP II

ERP

ERPII

1965

1980

1995

2000

\section{ERP EVOLUTION THROUGH VARIOUS STAGES: -}

Mugahed, Abdullah, \& Ambedkar, (2017) have nicely elaborated on the technological evolution of ERP through various stages. They say in the first stage in 1960s the centralised computing systems were developed which was mainly used for automating their inventory control systems. This was the first generation which witnessed centralized computing systems.

In the second generation the Material Requirement Planning popularly known as MRP was developed which mainly involved planning the product or part requirement according to master production schedule.

The third-generation software systems were called Manufacturing Resources Planning (MRP II) which emphasized on optimizing manufacturing process by synchronizing the materials with production planning requirements. MRP II included areas such as shop floor and distribution management, project management, finance, Human resource and engineering.

The fourth generation mainly in 1990s witnessed the power of ERP inter-

Journal of Technology Management for Growing Economies, Volume 9, Number 2, October 2018 
functional coordination and integration. In the late 90s ERP systems started targeting many sectors such as governments, service -oriented companies, and NPOs.

With the beginning of 2000s the ERP vendors included more modules and functions as add-ons to the core modules giving birth to extended ERP or ERP II systems. These ERP extensions includes advanced planning and scheduling, e-business solutions such as customer relationship management, supply chain management. In the early 2000s ERP system experienced a rapid progress because of $\mathrm{Y} 2 \mathrm{~K}$ problem and the European system threw the legacy system in a dilemma state. Hence many enterprises replaced legacy systems with newly fashioned ERPs.

Rashvanlouei, Thome, \& Yazdani (2015) in their work says that in the late 90s ERP systems started targeting many sectors such as governments, service -oriented companies, and NPOs. In the early 2000s ERP system experienced a rapid progress because of $\mathrm{Y} 2 \mathrm{~K}$ problem and the European system threw the legacy system in a dilemma state. Hence many enterprises replaced legacy systems with newly fashioned ERPs.

\section{ERP ENVIRONMENT}

The ERP environment of a manufacturing and service sector is pretty different from that of an educational sector. Chen (1999) says in a typical manufacturing environment the master production schedule is used to create production and purchase orders for low level components. MRP is continuously evolving and expanding. The difference mainly pertains to the firm's individual environment. The difference in ERP modules used between manufacturing and educational sector can be discussed as below

\begin{tabular}{|c|c|}
\hline Manufacturing and Service Sectors & Educational Sector \\
\hline $\begin{array}{l}\text { The ERP modules implemented in } \\
\text { manufacturing and service sectors are viz. } \\
\text { HCM, SD, MM, SCM, CRM, ABAP BI, } \\
\text { FI, CO, which are mainly part of ERP core } \\
\text { module. These modules were mainly made } \\
\text { on the environment of firm's business lines. }\end{array}$ & $\begin{array}{l}\text { The ERP modules implemented } \\
\text { in education sector are student's } \\
\text { admission, course enrolment, } \\
\text { student data management, course } \\
\text { management, library systems,FI } \\
\text { Alumni management, research } \\
\text { network. }\end{array}$ \\
\hline
\end{tabular}

\section{ERP IN THE EDUCATION SECTOR}

Implementation of ERP in academic industry is in a nascent stage. Universities and large higher secondary schools are implementing ERP for various purposes.

Journal of Technology Management for Growing Economies, Volume 9, Number 2, October 2018
Journey of

ERP from

Manufacturing 
Mitra, P. Mishra, S.
Sowan, (2017) also says that recently ERP is penetrating the educational sector to increase the quality of their academic and administrative services. In the universities ERP system is defined as an "information technology solution " which integrates all the business units and functions and autoes activities such as recruitment, admissions, financial aid, student records, and most academic and administrative services. University administrative services include human resources, billing, accounting, and payroll. On one hand, academic services include deployment, admission, registration, and all aspects of student records . On the other hand, university ERP systems that are implemented for academic purposes provide all administrative and academic functions. Universities have made important investments in ERP implementation in order to improve their business operations planning.

In India maximum implementation of ERP has happened in technical educational institutes (TEI). ERP is implemented in the HEI to improve and integrate the management and administration process for student registration, student activity, human resource system and financial processing (Bhat, Shroff, \& Bandi, 2013).

Unlike manufacturing, the Indian TEI offers a different set of functions, like admission of students (processing of application forms, candidate short listing, fee processing); course enrolment, student data management (e.g. attendance tracking, grade information); course management (e.g. enrolment, feedback on courses), asset management (contracts, grants), library systems, financial systems, alumni management and research networks. The benefits derived by implementing ERP in TEI are: functionality, improved security, efficiency and communication, enhanced technology and reporting, integrated information providing easier access to data along with user friendly software. As we all know that the main work of any ERP system is the data storage in a central database, therefore, data quality needs to be taken care of in ERP software. TEIs involve planning, administration and evaluation of efforts in order to incorporate data quality. User readiness was found to be negatively correlated with operational efficiency which resulted in optional handling of the software. By incorporating factors such as consistency, reliability and safety usability of the system can be improved (Goel, Kiran, \& Garg, 2011).

\section{People factor influencing ERP success in Manufacturing sector:}

While some researchers opine that adopting and adapting of technology is no longer an option now, it is rather a requirement (Bharathi, Vaidya, \& Parikh, 2012). On the others hand others find that there is resistance and other change related outcomes in the organisation reduces usage of ERP (Mayeh, Ramayah, \& Mishra, 2016; Samuel \& Kumar, 2014; Lambeck, Müller, Fohrholz, \& Leyh, 2014; Arekete, Ifinedo, \& Akinnuwesi, 2015).

Journal of Technology Management for Growing Economies, Volume 9, Number 2, October 2018 
Beeler, Saint-leger, Lyon, \& Moulin (2006) talks about cultural differences as the main reason behind diverse and conflicting values which creates to failure of ERP system. The end users who are habituated to particularistic culture, have to accept the universalist culture because of IT globalization. This difference in culture creates a gap and affects the adaptability. Levasseur (2010) calls the non-technical part of project failures to be the line managers, project managers. So, in order to bring a better and cumbersome environment for successful usage of ERP it is the human resources who have to work upon and find ways which can lessen the ratio of failure. Zulkifli, Ahmad, \& Fuzi (2013) considered the socio psychological factor 'reward' and social influence compensated with extrinsic motivation as a positive factor which leads to high system usage.

According to Amoako-Gyampah (2004) there are different people involved in an implementation process viz. top management, project managers, team leaders, trainers, end users and consultants, with their own individual interest and yield some amount of power. This power helps them to drive the implementation process. Samuel \& Kumar (2014) categorises power as positional and knowledge power. He also categorised users as :- transactional users, knowledge-power users, positional users. Amoako-Gyampah (2004) describes the managers of superficial power in the ERP project, who compose extreme leadership skills to keep the project ongoing, and also conduct regular meetings to keep a proper flow of information in the entire team.

Cereola, Wier, \& Strand, (2012) have worked on SME segment and say that IT knowledge, absorptive capacity and experience play a vital role in adoption of IS in SME to assimilate open source system. The assimilation of open source system brings a huge performance of ERP system. Venkatraman \& Fahd (2016) say, the main adoption problem in the SME is the misfit in implementation process due to non-alignment between vendors and business strategy. SMEs practice open source system which is available at nominal prices, they make implementation simpler and have sufficient features which suffice the SME requirement.

Coming to the post implementation stage, it has been found out that shared belief of all the people concerned about the system plays an important role in the success of ERP (Amoako-Gyampah, 2004). Sometimes the negative emotion of end users attached to the ERP system reduces his/her task efficiency. It always happens in the initial phases of the ERP implementation (Saeed, Abdinnour, Lengnick-Hall, \& Lengnick-Hall, 2010). Hence, active involvement of end users and their motivation is required. According to Nejib (2013) this involvement is mainly manifested by the participation of the user in the project. Active involvement of the users help to detect the problems

Journal of Technology Management for Growing Economies, Volume 9, Number 2, October 2018
Journey of

ERP from

Manufacturing 
Mitra, P. Mishra, S. specially the adequacy of the software. Reza Moohebat, Davarpanah Jazi, \& Asemi (2011) considers end users as front line soldiers who have direct contact with the system. User involvement is important because it enhances perceived control by bringing participation in the whole project plan. Shrivastava and Dave (2010) opine that user involvement is the participation and decision making capacity of a respondent. The feelings, thoughts and ideas are encouraged by top management. A collective user participation results in more satisfaction, acceptance, organisational commitment, and improved data. According to Lambeck et al., (2014) user satisfaction can also be formed from factors such as self-efficacy, experience and perceived usefulness, corporate culture.

\section{People factor influencing ERP success in Education sector:}

ERP implementation in educational institutes also face the similar challenge from people factor. It has been found out that forming a right team and selecting the right members who can understand the business process is very crucial (Shatat \& Dana, 2016). Due to the complexity of ERP, dedication and involvement of users is very essential in all stages of implementation (Shatat \& Dana, 2016). Further they mention that training should be conducted regularly to involve the users and get themselves involved in the system and accept the idea of change.

Communication is essential for successful implementation because, through communication the employees can be aware of the progress and understand the benefits of the software (Shatat \& Dana, 2016; Bologa et al., 2009). Bologa et al., (2009) say that typically in Universities due to the different groups and their varied objectives and interest in different fields the communication becomes very difficult. This difficulty can be eliminated by creation of trust, mutual respect, informal meetings and discussions with small groups. In university the communication is of a different structure where a strict control is seen by the project management team and top management to control the project resistance. Inter department communication is also essential for user and management for project monitoring. The lack of communication or unsteady communication can lead to lack of confidence between involved parts and increase in communication complexity.

Bhat et al. (2013) consider age an important factor for acceptance of ERP. It is noticed that ERP is gladly accepted by young staffs, which is showed by their eagerness to learn the software. Differences in acceptance to ERP also has been found among people with computer anxiety (Rabaa \& Gable, G. \& Bandara, 2009) and experience of using computers (John, 2015). Those who have computer self-efficacy have been found to be accepting ERP gladly (John, 2015).

Journal of Technology Management for Growing Economies, Volume 9, Number 2, October 2018 
Goel et al.(2011) found that lack of knowledge related to ERP system was one factor which lead to failure in implementation. Scarcity of resources and technology staff limited the benefits. Hence, training plays an important role in bringing success. Apart from this certain perceptual factors such as perceived relative advantage and perceived compatibility with his or her socio cultural values, beliefs, needs and his or her past experiences enhances ERP usage (John, 2015).

\section{The future trend and challenges of ERP :-}

In today's trend most organisations are operating their business process through ERP systems . Chen, (1999) says, these integrated systems provide a weak support in less data-intensive areas, such as supply chain planning, customer management marketing and sales. So the ERP developers developed supply chain optimization which provide solution to such weakness. Also the customer relationship management strategies seamlessly link the front office and back office operations to enhance competitive advantages.

But ERP change has to be balanced by behavioural change occurring in an organisation. The ERP enabled process are designed to grow in power and organisations also take time to grow with them. The pace with which the organisations learn to modify their behaviour as required become the most sustainable source of competitive advantage in future.

\section{DISCUSSION AND CONCLUSION}

With the increase in implementation of ERP in various sectors the research in this area is also growing to find out critical success factor, understand the determinants of usage, etc. On the technical aspect, various modules have been developed to fit into different environments of a given sector, industry or organisation. With the proliferation of education industry, the need for ERP has increased. Researchers have identified few gray areas to carry forward research in this sector. For example, Banswal (2015) emphasized on shifting attention from technical and human factors to users, task and system, and how these elements can increase the benefits of ERPs and create values. Hence, it is imperative to explore the factors that influence user acceptance of ERP.

It has also been found out that the vendors face the problem in reengineering in educational industry as they lack knowledge on the modules which has primarily become a major cause for technical failure. Along with technical inadequacy there are other psychosocial dynamics which influence ERP usage in technical institutions. Researchers are trying to explore such psycho-social aspects of education industry.

In most of the cases it has been found out that the technical competency
Journey of

ERP from

Manufacturing 
Mitra, P. Mishra, S. of the internal IT team of the universities is low. Particularly, they lack knowledge about the software. So after the implementation process when training comes in focus they are not able to impart proper training to the end users. This leads to lack of understanding of the technology and lack of adaptation of organisational change which leads to lesser usage. How to build an empowering technical team in educational institutes and how to map the training process and other change initiatives can be a potential research area.

\section{REFERENCES}

Abdullah, A. (2017). Evolution of Enterprise Resource Planning. Excel Journal of Engineering Technology and Management Science, 1(2), 1-6.

Abugabah, A., \& Sanzogni, L. (2010). Enterprise resource planning (ERP) system in higher education: A literature review and implications. International Journal of Human and Social Sciences, 5(6), 395-399. Retrieved from http://www.scopus.com/inward/record.url?eid=2s2.0-78651529516\&partnerID $=40 \& \mathrm{md} 5=6 \mathrm{ac} 410866 \mathrm{ec} 5187 \mathrm{a} 91 \mathrm{dc} 5 \mathrm{c} 20 \mathrm{~d} 4942332$

Amoako-Gyampah, K. (2004). ERP implementation factors: A comparison of managerial and end-user perspectives. Business Process Management Journal, 10(2), 171-183. https://doi. org/10.1108/14637150410530244

Antero, M. C. (2015). A multistage analysis of the development of enterprise resource planning (ERP) business practices. Copenhagen Business School.

Arekete, S., Ifinedo, P., \& Akinnuwesi, B. A. (2015). Antecedent factors to end-users' symbolic acceptance of enterprise systems: An analysis in Nigerian organizations. IEEE International Conference on Adaptive Science and Technology, ICAST, 2015-Janua. https://doi. org/10.1109/ICASTECH.2014.7068108.

Banswal, D. (2015). A Study on an Impact of Enterprise Resource Planning in Higher Education. KHOJ: Journal of Indian Management Research and Practices, 62-67.

Beeler, B. \& Saint-Léger, G. (2014). Understanding Technology Adoption from the "Multiple Cultures Perspective": The Case of a Successful Post-Implementation Recovery.Management international, 18(2), 169-180. https://doi.org/10.7202/1024201ar.

Bharathi, S. V., Vaidya, O., \& Parikh, S. (2012). Prioritizing and ranking critical success factors for ERP adoption in SMEs. AIMS International Journal of Management, 6(SEPTEMBER 2015), 23-40. https://doi.org/10.1504/IJAL.2015.071723

Bhat, J. M., Shroff, B., \& Bandi, R. K. (2013). User perceptions, motivations and implications on ERP usage: An Indian higher education context. Lecture Notes in Business Information Processing, 139 LNBIP, 90-105. https://doi.org/10.1007/978-3-642-36611-6_7

Bologa, R., Bologa, A. R., \& Sabau, G. (2009). Success factors for higher education ERPs. ICCTD 2009 - 2009 International Conference on Computer Technology and Development, 1(December 2009), 28-32. https://doi.org/10.1109/ICCTD.2009.142.

Cazan, A. M., Cocoradə, E., \& Maican, C. I. (2016). Computer anxiety and attitudes towards the computer and the internet with Romanian high-school and university students. Computers in Human Behavior, 55, 258-267. https://doi.org/10.1016/j.chb.2015.09.001

Cereola, S. J., Wier, B., \& Strand, C. (2012). Impact of top management team on firm performance in small and medium-sized enterprises adopting commercial open-source enterprise resource planning, 31(9), 889-907.

Chen, I. J. (1999). Planning for ERP systems : analysis and future trend. Business Process Management Journal, 7(5), 374-386

Esteves, J., \& Pastor, J. A. (2005). Understanding an ERP System Implementation in a Higher Education Institution: A Grounded Theory Approach. Qualitative Case Studies on

Journal of Technology Management for Growing Economies, Volume 9, Number 2, October 2018 
Implementation of Enterprise Wide Systems, 2132-2134.

Goel, S., Kiran, R., \& Garg, D. (2011a). A framework for efficient enterprise resource planning ( ERP ) implementation in technical educational institutions, 5(34), 13197-13204. https://doi. org/10.5897/AJBM11.1349

Goel, S., Kiran, R., \& Garg, D. (2011b). A Framework for Efficient Enterprise Resource Planning ( ERP) Implementation in Technical Educational Institutions. African Journal of Business Management, 5(34), 13197-13204. https://doi.org/10.5897/AJBM11.1349

John, S. P. (2015). The integration of information technology in higher education: A study of faculty's attitude towards IT adoption in the teaching process. Contaduria $Y$ Administracion, 60, 230-252. https://doi.org/10.1016/j.cya.2015.08.004

Lambeck, C., Müller, R., Fohrholz, C., \& Leyh, C. (2014). (Re-)Evaluating User Interface Aspects in ERP Systems -- An Empirical User Study. 2014 47th Hawaii International Conference on System Sciences, 396-405. https://doi.org/10.1109/HICSS.2014.57

Levasseur, R. E. (2010). People skills: Ensuring project success- A change management perspective. Interfaces, 40(2), 159-162. https://doi.org/10.1287/inte.1090.0473

Mayeh, M., Ramayah, T., \& Mishra, A. (2016). The role of absorptive capacity, communication and trust in ERP adoption. Journal of Systems and Software, 119(May), 58-69. https://doi. org/10.1016/j.jss.2016.05.025

Nejib, B. E. N. M. (2013). Determinants of Post Implementation Success of ERP In Tunisian Companies: An Empirical Study of The Moderating Role of The Technical Fit. International Review of Management and Business Research, 2(4), 1101-1113.

Nejib, B. E. N. M. (2013). Determinants of Post Implementation Success of ERP In Tunisian Companies: An Empirical Study of The Moderating Role of The Technical Fit. International Review of Management and Business Research, 2(4), 1101-1113.

Nizamani, S., \& Khoumbati, K. (2014). A Conceptual Framework for ERP Evaluation in Universities of Pakistan. Sindh University Research Journal, 45(3), 467-475. Retrieved from http://arxiv.org/abs/1402.0116

Nizamani, S., Khoumbati, K., Ismaili, I. a., Nizamani, S., Nizamani, S., \& Basir, N. (2015). S u r j s s. Si Ndh University Research Journal (Science Series), 47(2), 295-302.

Petter, S., Delone, W., \& Mclean, E. R. (n.d.). Journal of the Association for Information Systems The Past , Present , and Fu ture of "IS Success ," 13(February 2011), 341-362.

Rabaa, A., \& Gable, G. \& Bandara, W. (2009). ERP Systems in the Higher Education Sector : A Descriptive Case Study. Proceedings of the 20th Australasian Conference on Information Systems, 456-470.

Rabaa, A., \& Gable, G. \& Bandara, W. (2009). ERP Systems in the Higher Education Sector : A Descriptive Case Study. Proceedings of the 20th Australasian Conference on Information Systems, 456-470.

Rashvanlouei, K. Y., Thome, R., \& Yazdani, K. (2011). Functional and Technological Evolution of Enterprise Systems : An Overview.

Reza Moohebat, M., Davarpanah Jazi, M., \& Asemi, A. (2011). Evaluation of the ERP Implementation at Esfahan Steel Company Based on Five Critical Success Factors: A Case Study. International Journal of Business and Management, 6(5), 236-250. https://doi. org/10.5539/ijbm.v6n5p236.

Saeed, K. A., Abdinnour, S., Lengnick-Hall, M. L., \& Lengnick-Hall, C. A. (2010). Examining the Impact of Pre-Implementation Expectations on Post-Implementation Use of Enterprise Systems: A Longitudinal Study. Decision Sciences, 41(4), 659-688. https://doi.org/10.1111/ j.1540-5915.2010.00285.x

Samuel, R. D., \& Kumar, N. S. (2014). Factors determining the enterprise resource planning project-success in small and medium enterprises: Evidence from Indian cases. World Applied Sciences Journal, 31(14), 5-11. https://doi.org/10.5829/idosi.wasj.2014.31.
Journey of

ERP from

Manufacturing

\footnotetext{
Journal of Technology Management for Growing Economies, Volume 9, Number 2, October 2018
} 
Mitra, P.

Mishra, S. arsem.498

Semeon, G. ., Negash, S. ., \& Musa, P. . (2010). The success of student information management system: The case of higher education institution in Ethiopia. 16th Americas Conference on Information Systems 2010, AMCIS 2010, 6(July 2015), 4522-4532. Retrieved from http:// www.scopus.com/inward/record.url?eid=2-s2.0-84870307150\&partnerID=40\&md5=3ac1d $817787566 \mathrm{~d} 6614 \mathrm{~cd} 33 \mathrm{~d} 855 \mathrm{f} 3 \mathrm{~d} 75$

Shatat, A. S., \& Dana, N. (2016). Critical Success Factors across the Stages of ERP System Implementation in Sohar University : A Case Study, 3(1).

Shrivastava, M., \& Dave, S. (2010). Compatibility: Between Culture and Change. SCMS Journal of Indian Management, 7(1), 68-75. Retrieved from http://search.ebscohost.com/login.aspx ?direct $=$ true $\& \mathrm{db}=$ buh \&AN=48924585\& site=ehost-live

Sowan, I. K. (2017). University ERP Preparation Analysis : A PPU Case Study. International Journal of Advanced Computer Science and Applications, 8(11), 345-352.

Thakur, A. (2016). Enterprise Resource Planning (ERP) Implementation in Technical Educational Institutes: Prospects and Challenges. International Journal of Multifaceted and Multilingual Studies, 3(2), 1-5. https://doi.org/10.1890/09-2296.1.Abrams

Theodoros MITAKOS, Ioannis ALMALIOTIS, Anna DEMEROUTI (2010), An Auditing Approach for ERP Systems Examining Human Factors that Influence ERP User Satisfaction, Informatica Economică vol. 14, no. 1/2010, 78-92

Venkatraman, S., \& Fahd, K. (2016). Challenges and Success Factors of ERP Systems in Australian SMEs. Challenges and Success Factors of ERP Systems in Australian SMEs, 4(2), 20. https://doi.org/10.3390/systems4020020.

Zulkifli, N., Ahmad, J., \& Fuzi, S. F. S. M. (2013). Social-psycho Issues of Enterprise Information System Usage among Government Outsource Vendors Comprising Malaysian Small Medium Enterprises. 24th Australasian Conference on Information Systems 4-6 Dec 2013, Melbourne, (December), 4-6. https://doi.org/10.3127/ajis.v18i3.1094 